\title{
Away with the system review: a plea for parsimony
}

\author{
B I Hoffbrand
}

It has been standard practice for many years to teach clinical medical students to include a review of the body systems as a routine, not to be missed, part of the initial history taking. This exercise has been variously called the system review, ${ }^{1 \cdot 3}$ functional inquiry, ${ }^{4}$ systemic inquiry, ${ }^{67}$ and symptom review. ${ }^{8}$ The authors generally advocate asking every patient specific questions related to possible disease in each system. As many as 60 questions may be asked, ${ }^{9}$ less those already asked with the presenting complaints, but with additional questions if any of the routine ones prove positive. Of the clinical methods texts reviewed, only Swash and Mason ${ }^{10}$ in listing their "routine questions" suggest that only those relevant to the system suggested by the presenting complaints should be put. All eight of the 13 medical schools in the south east of England who responded to a personal letter asking for details of notes given to clinical medical students embarking on their introductory course currently recommend one or more of the above textbooks or provide notes with instructions for a system review, or both.

\section{Ostensible value of the system review}

The rationale offered for the system review is that the patient may not have mentioned important symptoms through not appreciating that they were important or because of embarrassment. ${ }^{6}$ Only by asking the listed questions in every case can it be certain that all the information from the history, helpful in reaching a diagnosis ${ }^{4}$ and alerting the inquirer to other coincidental pathology, ${ }^{78}$ has been obtained.

The value of the system review as a method of screening for unexpected disease seems to be accepted as a self evident truth. To my knowledge there is no documented evidence that finding appreciable unexpected disease in this way is likely to be other than a very occasional event. This process makes unwarranted assumptions about the sensitivity and specificity of the individual symptom sought, about the prevalence of the symptom in a normal population, and hence about the probability of disease. "In contrast with the relative reproducibility of laboratory tests there is a high degree of observer variability in history taking $^{12}$ that can only devalue it further as a tool for screening.

\section{Interference with clinical problem solving}

A much more serious criticism of the system inquiry is that, far from helping in diagnosis, it almost certainly seriously interferes with the diagnostic process. Studies of clinical problem solving have shown that clinicians form tentative diagnostic hypotheses early during a consultation on the basis of minimal clinical information. Subsequent data collection, be it by history taking, physical examination, or investigation, is made with a view to its usefulness in testing the hypotheses. ${ }^{13}$ This hypothetico-deductive method serves the important purpose in problem solving of reducing the potential area of inquiry, the "problem space" of Newell and Simon. ${ }^{1+}$ The system review may
A much more serious criticism of the system inquiry is that, far from helping in diagnosis, it almost certainly seriously interferes with the diagnostic process

well add to the problem space or at best have a smoke screen effect on attempts to more clearly define the problems. Campbell ${ }^{15}$ has likened the tackling of problems by the hypothetico-deductive approach to map construction, to enable the inquirer to find his way expeditiously about the neighbourhood of the diagnostic goal. The system review seems designed to lay false trails.

Gale and Marsden ${ }^{16}$ showed that large quantities of irrelevant information-just the sort that the system review throws up-interfere with the generation of hypotheses particularly for the individual with a small knowledge base. As the major cause of incorrect diagnosis may well be failure to generate and consider the relevant diagnostic hypotheses ${ }^{17}$ the potential for damage to the diagnostic process of the system review seems considerable. The number of hypotheses that can be held in the memory and evaluated at any one time is limited. ${ }^{18}$ Elstein and Bordage ${ }^{17}$ believe that excessive data collection interferes with clinical inference and reasoning by overloading the capacity of the system. Gill et $a l^{19}$ found in their study that diagnostic error was due less to faulty data acquisition than to failure to manipulate large volumes of data correctly.

\section{Pleas for parsimony}

The increasing interest in and understanding of the processes of clinical problem solving have been contrasted with the lack of impact these advances have had on the training of medical students..$^{20}$ The barrier to promoting the insights provided by decision analysis, probability theory, and cognitive science may well lie in large part in the manner in which they are advocated. Overly technical language and programmes for management based on mathematical and statistical formulas are not likely to win the hearts and minds of many clinicians. But the initial hurdle of teaching the teachers is being tackled. Schwartz, ${ }^{21}$ Kassirer, ${ }^{22}$ and Campbell ${ }^{15}$ have made eloquent pleas for clinicians to teach hypothesis generation and testing and the fact finding strategies needed for it rather than stereotyped routine assessments. Many probably do so already. I suspect, however, that a study of house officers today might not show materially different results from those of a study of 15 years ago. This found young doctors, after five years of medical school training, to be conducting stereotyped clinical interviews as nothing more than screening clerks with little ability to embark on decision making. ${ }^{23}$

These authors and others place great emphasis on limiting observations as far as possible to ones that are likely to count in the generation, verification, and falsification of hypotheses. Schwartz ${ }^{21}$ states clearly that clinical facts are useful only if they can be employed in solving clinical problems. Campbell ${ }^{15}$ 
makes a plea for as much attention to be paid to economy as to thoroughness and castigates the "mindless work-up." Macartney ${ }^{24}$ suggests that after accuracy the most important criterion by which a method of diagnosis should be judged is parsimony, a dictionary definition of which is "praiseworthy economy in the use of means to an end." He describes as a blunderbuss approach the traditional method taught to medical students of full history and examination followed by working out what is wrong. (This sequence - history, examination, differential diagnosis - is clearly recommended in one popular text $t^{5}$ and was advocated by at least one distinguished London medical school..$^{25}$ )

Clearly the system review contributes only one element to the blunderbuss approach to diagnosis. Other aspects of history taking, such as that of family and past illness and drugs taken, are generally taught as an exercise in cataloguing rather than in seeking hypothesis generating and testing information. The overdetailed physical examination, tiring to patient and examiner alike, and the untargeted battery of laboratory and imaging investigations all play a part. But while considerable attention has been paid to the need to use investigations parsimoniously ${ }^{26}$ there are no easily measurable costs and hazards in an undirected blanket approach to the clinical encounter. There is now much evidence that, though difficult to quantitate, they are there none the less.

\section{Other rewards of dropping the system review}

Doing away with the system review, apart from helping to concentrate on the development of skills in clinical problem solving, would yield other benefits. Kassirer' ${ }^{22}$ indictment of the traditional case presentation as the epitome of boredom must strike a chord with teacher and taught alike. The large contribution that the system review makes to the tedium is underlined by the speed with which I and fellow examiners in MB finals stifle at birth the attempts of candidates to embark on their system review. Getting the system review out of the system should shorten the length of clinical notes, letters, and summaries to the greater good of communication among doctors. Wright and Macadam $^{25}$ in discussing the problems that interfere with communication between patient and doctor implicate uncritical zeal for the structured consultations of traditional teaching. The system review must also contribute, in Balint's "elimination by appropriate physical examinations," to the difficulties faced in the diagnosis of problems of the whole personality by doctors taught by the traditional approach. ${ }^{27}$

Perhaps the most telling indictment of the system review is that experienced clinicians do not use it. The exigencies of clinical practice alone could not permit such a time consuming process, laying aside its unproven utility and potential for interference. Depending on the complexity of the clinical problem, many of the questions will be asked anyhow, but for problem solving, not by rote. We all indulge to some extent in routine data collection by history and examination depending on the needs of our own practice and our interests. This serves as a hedge against premature restriction of working hypotheses and also as a labour saving device to reduce cognitive strain. ${ }^{17}$ The routine measurement of blood pressure is one such observation of proven utility.

\section{Potential value of system related symptoms in problem solving}

Is the system review an unmitigated disaster? The short answer, despite what has gone before, is "no." Through the catechism of the system review the student learns to associate symptoms with systems.
This will be an aid to the critical step of hypothesis generation and testing which Elstein and colleagues ${ }^{13}$ believe is the natural bent of most students anyhow. Unfortunately, the review as taught is unrefined as well as undirected and does not take advantage of the fact that symptoms have great value as, variously, pointers to anatomy, pathology, and physiology (disturbances of function). The tiro clinical student could with his or her preclinical knowledge, and with instruction in the diagnostic importance of symptoms, start generating and testing hypotheses from the start, while embarking on the critical process of learning about diseases.

\section{Perhaps the most telling indictment of the system review is that experienced clini- cians do not use it}

Clinical training would be devoted to using probability and utility in hypothesis generation, to learning the techniques of physical examination to gather relevant information, and to the all important, but undertaught goal of the clinical process - namely, optimal management of the patient. Diagnosis is a means to an end, not an end in itself. The undirected collection of clinical information for "diagnosis" too often side tracks the clinician who forgets this vital fact. ${ }^{2428}$

\section{Conclusion}

The art of the clinical process lies in seeking the relevant information to achieve the goal of optimal care for our patients. This means asking the right questions, not every question, be it by history, examination, use of diagnostic aids and of the very pathology reports, electrocardiograms, and $x$ rays requested. Hampton and colleagues' much quoted study ${ }^{29}$ shows the supreme importance of the history in reaching the correct diagnosis. The consequence of this is not the more history the better, but that history taking is far too valuable an instrument to be used blunt. Others $^{15212224}$ have called for a sea change in how medical students are taught clinical methods. I believe that those concerned with medical school clinical curricula and didactic textbooks should, as a move in this direction, give serious thought to eradicating the eminently expendable system review from their teaching. Among many benefits this would be a blow against inculcating the attitudes of defensive medicine in the young and impressionable.

1 Bouchier IAD, Morris JS. Clinical skills. 2nd ed. London: Saunders, 1982:9. 2 Tunbridge D. Notes on clinical method. Manchester: Manchester University Press, 1982:4.

3 Bates B. A guide to physical examination and history taking. 4th ed. Philadelphia: Lippincott, 1987:5.

4 Seymour CA. Introduction to clinical clerking. Cambridge: Cambridge University Press, 1984:12.

5 Turner $\mathrm{R}$, Blackwood $\mathrm{R}$. Lecture notes on history taking and examination. Oxford: Blackwell Scientific Publications, 1983:7.

6 Macleod J, Munro JF. Clinical examination. 4th ed. Edinburgh: Churchill Livingstone, 1985:3.

7 Edwards CRW. In: Macleod J, Munro J, eds. Clinical examination. 7 th ed. Edinburgh: Churchill Livingstone, 1986:4.

8 Davis A, Bolin T, Ham J. Symptom analysis and physical diagnosis. 2nd ed. Sydney: Pergamon, 1985:6.

9 Parkins RA, Pegrum GD. The basis of clinical diagnosis. London: Pitman Medical, 1974:2.

10 Swash M, Mason AS. Hutchinson's clinical methods. 18th ed. London: Baillière Tindall, 1984

11 Sox HC. Probability theory in the use of diagnostic tests. Ann Intern Med 1986;104:60-6.

12 Cochrane AL, Chapman PJ, Oldham PI. Observers' errors in taking medical histories. Lancet 1951:i:1007-9.

13 Elstein AS, Shulman LS, Sprafka SA. Medical problem solving: an analysis of clinical reasoning. Cambridge, Mass: Harvard University Press, 1978.

14 Newell A, Simon HA. Human problem solving. Englewood Cliffs NJ: Prentice Hall, 1972.

15 Campbell EJM. The diagnosing mind. Lancet 1987;i:849-51.

16 Gale J, Marsden P. Medical diagnosis from student to clinician. Oxford: Oxford University Press, 1983:19. 
17 Elstein AS, Bordage G. In: Dowie J, Elstein A, eds. Professional judgement; $a$ reader in clinical decision making. Cambridge: Cambridge University Press, 1988:109-29.

18 Barrows HS, Norman GR, Neufeld VR, Feightner JW. The clinical reasoning of randomly selected physicians in general medical practice. Clin Invest Med 1982;5:49-55.

19 Gill PW, Leaper DJ, Guillou PJ, et al. Observer variation in clinical diagnosis - a computer-aided assessment of its magnitude and importance in 552 patients with abdominal pain. Methods of Information in Medicine 1973;12:108-13.

20 Anonymous. Diagnosis: logic and psycho-logic [Editorial]. Lancet 1987;i: 840-1.

21 Schwartz WB. Decision analysis - a look at the chief complaints. N Engl f Med 1979;300:556-9.

22 Kassirer P. Teaching clinical medicine by iterative hypothesis testing; let's preach what we practice. N Engl F Med 1983;309:921-3.
23 Leaper DJ, Gill PW, Staniland JR, et al. Clinical diagnostic process; an analysis. Br.Med f 1973;ii:569-73.

24 Macartney FJ. Diagnostic logic. Br Med f 1987;295:1325-31.

25 Hoffbrand BI. Diagnosis and decisions - can we do better? Postgrad Med f 1987;63:729-30.

26 Wright HJ, Macadam DB. Clinical thinking and practice: diagnosis and decision in patient care. Edinburgh: Churchill Livingstone, 1983:69.

27 Balint M. The doctor, his patient and the illness. 2nd ed. Edinburgh: Churchill Livingstone, 1964

28 Hoffbrand BI. Diagnostic process. Lancet 1987;i 278-9.

29 Hampton JR, Harrison MJG, Mitchell JRA, et al., Relative contributions of history-taking, physical examination, and laboratory investigation to diagnosis and management of medical outpatients. Br.Med f 1975;ii:486-9.

(Accepted 28 December 1988)
This article and the one that follows it by William Laing are the seventh and eighth in a series of articles on the white paper Working for Patients and its accompanying working papers. The series started on 18 February (p 437) with another article by Ray Robinson.

\title{
NHS Review
}

\section{Self governing hospitals}

\author{
Ray Robinson
}

The devolution of decision making to the local operational level is one of the government's main objectives for the NHS. This is expected to secure local commitment; to produce services that are more responsive to the needs of patients; and to achieve greater value for money.' Encouraging the establishment of self governing hospitals is a key component of the policy designed to meet these aims.

Self governing hospitals will operate as independent trusts within the NHS. Each trust will be run by a board of directors with the chairman appointed by the Secretary of State. The board will be responsible for determining overall policy, while day to day management will be the responsibility of the general manager. Trusts will derive their income from service contracts obtained from district health authorities, general practitioner budget holders, and private patients. The government views competition between trusts, other NHS hospitals, and private hospitals as a mechanism for increasing efficiency and patient choice.

Initially it is intended that trusts will be restricted to major short stay hospitals with over 250 beds, although eventually other hospitals are expected to become eligible for self governing status.

- The government has a flexible definition of a self governing hospital

- Self governing hospitals could offer a range of community based services as well as acute care

- There could be self governing community units

- Neighbouring hospitals offering complementary services could combine into a single self governing unit.

Most of the advantages expected to result from self government derive from the greater autonomy that hospitals will be given to manage their own affairs. As in the case of the government's privatisation programme greater freedom from centrally imposed restrictions and bureaucratic control is expected to improve management's performance. Two main areas where this will apply are employment policy and capital spending.

\section{Employment policy}

Self governing hospitals will be given the freedom to determine their own staffing levels, rates of pay, and conditions of service. This freedom will cover all categories of staff, including doctors and nurses. The white paper argues that it is particularly important that trusts should be able directly to employ their own consultants. In determining rates of pay they may find it convenient to adopt national agreements. Alternatively, they may opt for arrangements that suit their local labour market conditions. Clearly, the government intends to remove what it sees as restrictive practices on pay and employment and to encourage a far more competitive labour market. What consequences can be expected to result from these changes?

\section{... doctors can also expect to be affected by the emergence of salary differentials.}

Freedom to determine rates of pay will almost certainly result in the emergence of wage and salary differentials between hospitals. Hospitals that are successful in competition for service contracts will be able to offer higher rates of pay to attract good quality staff. Similarly, hospitals located in areas with tight labour markets will have more freedom to offer competitive wages and salaries. In some cases, of course, higher rates of pay will lead to higher unit costs and place hospitals at a relative disadvantage when bidding for service contracts. In other cases improvements in productivity at more efficient hospitals can be expected to offset higher rates of pay.

The ability to determine their own rates of pay will offer more flexibility and may work to the advantage of self governing hospitals, but it could have deleterious effects on staff recruitment and retention at other NHS hospitals. Nursing staff, for example, might be expected to respond to opportunities to earn better salaries in self governing hospitals, especially if salaries in other hospitals continue to be restricted by national pay agreements. Some NHS hospitals are already suffering from the loss of key nursing staff to the private sector in specialties such as intensive care and theatre nursing. Competition from self governing hospitals may well exacerbate this type of problem.

Doctors can also expect to be affected by the emergence of salary differentials. Apart from variations in rates of pay between hospitals there may well be greater variation within hospitals. Some specialties will hold more revenue generating potential than others. In a system of workload funding there will be an incentive to link salaries more closely to the income generated by individual doctors and specialties. How far and fast this process will develop is difficult to predict.

Similar uncertainties surround changes in conditions 